\title{
Commentary: Nuancing the Meaning of Cultural Diversity
}

\author{
Cristina Jayme Montiel and Ma. Elizabeth J. Macapagal \\ Ateneo de Manila University
}

\begin{abstract}
$T^{\text {nis }}$ he featured articles in the section on cultural diversity across the Pacific address important cultural issues in psychology as applied to psychopathology (Marsella \& Yamada, 2011), intercultural relations and acculturation (Berry, 2011) and the phenomenon of culture shock (Furnham, 2011). We appreciate how the three articles offer a wide multidisciplinary lens and view mental problems from this broader vantage point. Beyond narratives of biology and individual personality dispositions, the authors include an anthropologists' eye to viewing mental illness (Marsella \& Yamada, 2011), use sociological explanations of intergroup relations in a multicultural model of acculturation (Berry, 2011) and refer to demographic migration patterns to elucidate culture shock among foreign students (Furnham, 2011).The contribution of this set of writings lies in its insightful emphasis on how culture interfaces with one's subjective life. Our essay unpacks the cultural lens used in the psychological accounts, points out conceptual spaces that are largely unexplored in cross-cultural psychology (something that is observed and lamented by these authors in their articles here and elsewhere) and suggests avenues for future research about cultural diversity.
\end{abstract}

Keywords: cultural diversity, cultural identity, intergroup asymmetry, Pacific Rim

\section{Unpacking the Cultural Lens}

In general, the three articles juxtapose cultural differences between the western world and a world beyond western borders. For example, Marsella and Yamada (2011) refer to western psychiatry and psychology, and then present richly illustrated thick descriptions of nonwestern mental illness and its determinants. Further, both Berry (2011) and Furnham's (2011) storylines about cultural diversity revolve around nonwestern new settlers moving to the West. Berry's (2011) article examines acculturation and intercultural relations in western settler societies like Australia, Canada, New Zealand and the United States. The choice of the adjective 'settler' (Berry, 2011, p. 97) connotes a movement away from a nonwestern place, a movement that ends in a western country. On a similar note, although Furnham's (2011) account of culture shock includes a few accounts of Americans and Europeans adjusting to nonwestern cultures, this particular article largely focuses on overseas students' experiences as they adapt to campus lifestyles.

We posit however, that the everyday cultural heterogeneities that face peoples in the Pacific Rim are not about hemispheric - West versus non-West - dialec- tics, but rather about intrasocietal variations across religions, linguistic ethnicities and social class. Societies in the Pacific Rim region are, of course, defined by tremendous linguistic and cultural diversity. For example, Vietnam has 23 dialects; in the Philippines 40 dialects are spoken (Trumbull, 2002) and Papua New Guinea has 852 different languages (Reilly, 2008). Furthermore, cultural distinctions across groups that live side-by-side with each other may be stark enough to ignite ethnopolitical wars in the region. Intrasocietal wars have erupted between ethnic groups such as the Chinese and Malays in Malaysia, and Muslims and Christians in both the Philippines and Indonesia.

Hence, the social meaning of cultural diversity among peoples in the Pacific Rim may be different from the meaning embedded in the storylines of these particular three featured articles. ${ }^{1}$ In particular, the intrasocietal cultural dialectics might be comparatively more salient to many peoples in the Pacific Rim.

\section{Conceptual Spaces About Cultural Diversity}

We note some conceptual openings and opportunities for expansion in the arguments about cultural diversity 
in the Pacific Rim. These become apparent when we use the Pacific Rim's culture-of-origin as a pivotal referential point, including the role of intergroup asymmetry. In particular, we emphasise that groups are not only different but also unequal.

\section{Recognising Context and Identities Associated With One's Pacific Rim Home Country}

We appreciate the use of ecology as a framework for understanding acculturation and the problems emanating from cultural differences. We commend the featured articles' emphasis on context, because indeed an ecological view includes a wider range of factors that impinge on individual psychological conditions. At the same time, the contextual considerations raised in explaining a psychology of acculturation (Berry, 2011) and culture shock (Furnham, 2011) focus on elements in the ecology of destination countries. For example, in Berry's (2011) article acculturation processes are somewhat embedded in intercultural relations in various destination countries. Such patterns of intercultural relations can be viewed as either a melting pot or a multicultural model. The discussion of culture shock likewise focuses on conditions in receiving countries, as students adjust to foreign schools. The article calls for counselling services and friendship networks to assist the young adolescent student. While such a destination focus is important, (e.g., context in destination countries can facilitate mental wellbeing among migrants) it can be expanded.

The featured articles do not, in this particular collection, openly discuss and align their ideas with more home-country contextual factors. Although psychopathology is richly described in a narrative sensitive to home-country language and practices (Marsella \& Yamada, 2011), it is left to the reader to elaborate on contextual considerations that may psychologically wound or heal individuals and communities. Such weighted contextual considerations may include, for example, negative presses such as political upheavals and ethnic strife, high crime rates, extreme poverty and a constant request for money from the emigrant by families in their home countries. Home-country context may likewise facilitate psychological wellbeing by providing, for example, loving family ties and lifelong friendships.

Local considerations are important not only for most Pacific Rim peoples who are non-migrants, but also for emigrants who have left for more materially comfortable countries. With the bourgeoning of the internet and internet-based forms of communication like Skype ${ }^{\mathrm{TM}}$, emotional and financial ties remain active in relation to one's country of origin.

Conceptual issues about shifting cultural identities could also be further explored. Cultural identity refers to the ways in which individuals define themselves in relation to the cultural groups to which they belong
(Berry, 1980; Markus \& Kitayama, 1991; Triandis, 1995). Furnham (2011) touches on this in discussing a model for understanding culture shock which posits that cross-cultural transition includes alterations in one's cultural identity (Zhou, Jondol-Snape, Toping, \& Todman, 2008). Marsella and Yamada (2011) also make reference to cultural identity as one of the criteria in culture-bound syndromes. Moreover, Berry (2011) mentions cultural identity briefly claiming that, in multicultural settings, security in one's own identity underlies the possibility of accepting others.

We believe that there might be important added differences in the way that cultural identity changes take place in economically more 'developed' settings versus the way that it does in the many economically 'developing settings' of the Pacific Rim. The Pacific Rim is certainly multicultural in nature. But unlike some sectors of the melting pots or multicultural settings in more developed societies, the Pacific Rim hosts cultural groups that are nonmigratory and have lived on their ethnic groups' territorial space for over hundreds and thousands of years. Indeed, such groups may hold cultural identities more passionately and with more resistance to change without being any less connected to global networks and other forms of $21 \mathrm{st}$ century life.

Other researchers recognise the added complexities of cultural identities in a global diaspora. Bhatia (2007) claims that if 'psychology anchored in the politics of culture is to become relevant in the contemporary global world, it must pay attention to the ways in which diasporic, hyphenated and hybridized identities are being formed across first world metropolitan cities.' (pp. 314-315). As foreigners and migrants recreate their culture, rituals and practices from their home country, they also recreate their identities (Bhatia, 2007). These identities may be multifaceted rather than bicultural, for example involving both one's new and home cities as well as countries.

\section{Intergroup Asymmetry: Groups Are Not Only Different, They Are Also Unequal}

We wish to emphasise that intercultural relationships, especially between western and nonwestern groups, are not only different but also unequal. Influential western discourses identify and label psychological phenomena associated with cultural diversity worldwide. We appreciate how Marsella and Yamada (2011) take pains to show how narratives in psychiatry and psychology assume a western lens, and further dominate the global understanding of psychological illness and wellbeing. Their article challenges attempts to homogenise classification and diagnostic systems based on western views. They criticise the western bias implied in the label 'culture-bound' disorders; because it implies that only nonwestern countries have disorders shaped by culture. 
Discussions about culture are indeed asymmetrically culture-bound.

Intercultural asymmetry also lies in the perceived and actual material difference between plentiful societies in the West and poverty-marked populations in most countries in the Pacific Rim. Asymmetric cultural relations, however, are not only hemispheric but also domestic. Looking more closely at interethnic relations within multiple tribal/ethnic societies in the Pacific Rim, one would likewise note that there is usually one ethnic group that dominates its neighbouring ethnic groups. Some examples of asymmetrically powerful ethnic groups in the Pacific Rim are the Han Chinese in China, Javanese in Indonesia, Christians in the Philippines, mestizos of Mexico, Chinese in Singapore and Khmers in Cambodia.

Along with material intergroup inequity arises a sense of being inferior and powerless when dealing with peoples in top groups. For example, the asymmetric relation makes a distinction between cultural difficulties associated with nonwestern newcomers (mostly new settlers ) in economically 'developed' societies, and western visitors (e.g., tourists, business executives and aid workers) to most of the Pacific Rim societies. Cultural experiences of adjustment, acculturation, even culture shock, multiply when coupled with perceived material inferiority and powerlessness relative to the host group. Interestingly, Berry (2011) acknowledges that in intercultural relations, one group is usually more dominant over the others. The solution offered to such dominance is a symmetric solution rather than one that factors in the asymmetry. Because Berry (2011) calls for mutual accommodation among all groups living together in the diverse society, the initial asymmetry will likely still remain.

\section{Future Research About Cultural Diversity in the Pacific Rim}

We highlight the significant contributions of the three articles as they provide a multidisciplinary understanding of the peoples in the Pacific and attend to cultural issues in psychology. The featured articles emphasise the use of culture as a lens to construct reality and as a framework to understand individual and collective behaviours. We also note opportunities for conceptual expansion related to the greater recognition of context and identities associated with one's Pacific Rim home country.

We suggest that future research utilise an everwidened lens on cultural diversity among peoples in the Pacific Rim. Such an expanded lens would include not only West/non-West comparisons, but also intrasocietal cultural variations. Moreover, future research may also consider the role of intergroup asymmetry as essential to the understanding of cultural heterogeneity.

We further propose that future research use the Pacific Rim's culture-of-origin and home-country contextual factors as critical points of reference, because the majority of Pacific Rim peoples are nonmigratory within their own societies. Social scientists may also want to look into narratives about shifting cultural identities and how subjective landscapes of one's home nation persist amidst geographic mobility.

Perhaps future researchers can likewise study the positive subjective experiences of cultural diversity. The restricted focus on cultural diversity as pathologic may need to be examined more closely. Concepts associated with positive psychology such as hope, wisdom, courage, spirituality or perseverance (Hart \& Sasso, 2011; Seligman \& Csikszentmihalyi, 2000) may be explored in relation to the subjective experience of cultural diversity in the Pacific.

In summary, future researchers on cultural diversity in the Pacific Rim may: (a) further consider nonmigrant samples that comprise the majority of the peoples in the Pacific Rim, (b) focus on local cultural identities and identity shifts associated with geographical mobility, (c) highlight intergroup vertical power structures in which cultural diversities are embedded and (d) further investigate the positive experiences and outcomes of diversity. These are all opportunities that the current lead articles, and the models they discuss, either explicitly or implicitly highlight.

\section{Reflexivity of Researchers in the Pacific Rim}

A final point we wish to make is the appreciation of the authors' reflexivity in the articles. Although himself a western psychologist, Berry (2011) concedes that his interest in studying culture came about because of his relationships with different people from varied cultures. Furnham (2011) also ended his article with a personal journey in writing two significant books on the topic of culture shock. Clearly, all the authors in the three articles have personal experiences of relating with people from varied cultures, which is something that the people from the Pacific Rim share. We believe it is important for scientists to acknowledge how their personal experiences shape their research interests.

As we write this commentary, we also wish to reflexively acknowledge our identities. We were born and grew up in the Philippines, a developing nation in the Pacific Rim, where many of our best citizens are enticed overseas by the prospect of greater economic and academic opportunities. Further, most of our formal academic training took place in the Philippines, as we both earned our undergraduate and doctoral degrees from Filipino universities. Much of our previous and current research work recognises asymmetric power relations and structural inequalities. As such, our comments are grounded using a home-grown and structural lens.

\section{Endnote}

1 We do recognise that these three particular articles may not fully capture the full scope of the authors' ideas on these subjects. 


\section{References}

Berry, J.W. (1980). Acculturation as varieties of adaptation. In A.M. Padilla (Ed.), Acculturation: Theory, models, and some new findings (pp. 9-25). Boulder, CO: Westview.

Berry, J.W. (2011). Intercultural relation and acculturation in the Pacific region. Journal of Pacific Rim Psychology, 4(2), 95-102.

Bhatia, S. (2007). Rethinking culture and identity in Psychology: Towards a transnational cultural psychology. Journal of Theoretical and Philosophical Psychology. 28(1), 301-321.

Furnham, A. (2011). Culture shock: Literature review, personal statement, and relevance for the South Pacific. Journal of Pacific Rim Psychology, 4(2), 87-94.

Hart, K., \& Sasso, T. (2011). Mapping the contours of contemporary positive psychology, Canadian Psychology, 52(2), 82-92.
Markus, H.R., \& Kitayama, S. (1991). Culture and the self: Implications for cognition, emotion, and motivation. Psychological Review, 98, 224-253.

Marsella, A., \& Yamada, A.M. (2011). Culture and psychopathology: Foundations, issues, directions. Journal of Pacific Rim Psychology, 4(2), 103-115.

Reilly, B. (2008). Ethnic conflict in Papua New Guinea. Asia Pacific Viewpoint, 49(1), 12-22.

Seligman, M.E.P., \& Csikszentmihalyi, M. (2000). Positive psychology: An introduction. American Psychologist, 55, 5-14.

Triandis, H.C. (1995). The psychological measurement of cultural syndromes. American Psychologist, 51, 407-415.

Trumbull, C. (Ed.). (2002). 2002 Britannica book of the year. Chicago: Encyclopedia Britannica.

Zhou, Z., Jondol-Snape, D., Toping, K., \& Todman, J. (2008). Theoretical models of culture shock and adaptation in international students in higher education. Studies in Higher Education, 33(1), 63-75. 